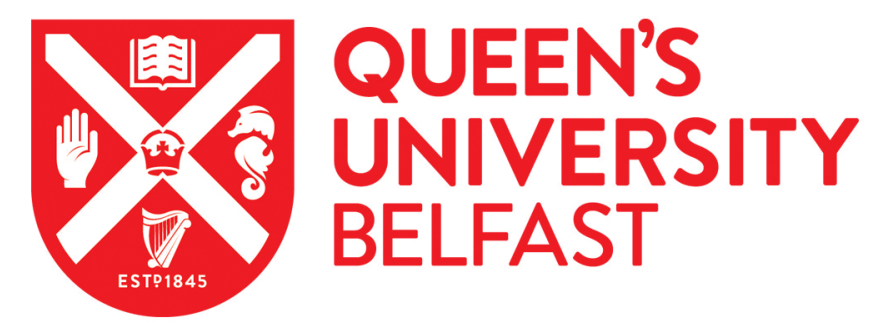

\title{
Playful pigs: early life play-fighting experience influences later life contest dynamics.
}

Weller, J., Camerlink, I., Turner, S., Farish, M., \& Arnott, G. (2019). Playful pigs: early life play-fighting experience influences later life contest dynamics. Animal Behaviour.

https://doi.org/10.1016/j.anbehav.2019.09.019

\section{Published in:}

Animal Behaviour

\section{Document Version:}

Peer reviewed version

Queen's University Belfast - Research Portal:

Link to publication record in Queen's University Belfast Research Portal

\section{Publisher rights}

Copyright 2019 Elsevier.

This manuscript is distributed under a Creative Commons Attribution-NonCommercial-NoDerivs License

(https://creativecommons.org/licenses/by-nc-nd/4.0/), which permits distribution and reproduction for non-commercial purposes, provided the author and source are cited.

\section{General rights}

Copyright for the publications made accessible via the Queen's University Belfast Research Portal is retained by the author(s) and / or other copyright owners and it is a condition of accessing these publications that users recognise and abide by the legal requirements associated with these rights.

\section{Take down policy}

The Research Portal is Queen's institutional repository that provides access to Queen's research output. Every effort has been made to ensure that content in the Research Portal does not infringe any person's rights, or applicable UK laws. If you discover content in the Research Portal that you believe breaches copyright or violates any law, please contact openaccess@qub.ac.uk. 


\section{Playful pigs: early life play-fighting experience influences 2 later life contest dynamics}

3

4 5

6

7

8

9

10

Jennifer E. Weller ${ }^{1 *}$, Irene Camerlink ${ }^{2}$, Simon P. Turner ${ }^{3}$, Marianne Farish ${ }^{3}$, Gareth Arnott $^{1}$

1. Institute for Global Food Security, School of Biological Sciences, Queens University

Belfast, Belfast, U.K.

2. Institute of Animal Husbandry and Animal Welfare, University of Veterinary Medicine Vienna (Vetmeduni), Vienna, Austria

${ }^{3}$ Animal Behaviour \& Welfare, Scotland's Rural College (SRUC), Edinburgh, U.K.

Received 16 April 2019

Initial acceptance 19 June 2019

Final acceptance 15 August 2019

MS number 19-00271

*Correspondence: J. E. Weller, School of Biological Sciences, Queens University Belfast, 19 Chlorine Gardens, Belfast BT9 5DL, U.K.

E-mail address: jweller01@qub.ac.uk

Animal contests are costly and predicted to be won by the individual with the higher resource-holding potential (RHP). Weight is often used a proxy for RHP; however, victory does not always go to the heaviest competitor, indicating that other traits may also contribute to RHP. Here we investigated the effect of preweaning play-fighting experience on postweaning contest behaviour in the domestic pig, Sus scrofa. We predicted that individuals that played more would win contests later in life. Play-fighting experience was also predicted to influence contest escalation behaviour, on both an individual and a dyadic level. Lastly, a pre-established framework and eight contest cost measures were used to establish whether competing individuals gather/use information regarding play-fighting experience as part of an assessment strategy. Play-fighting experience was recorded for socialized and control litters before weaning and contests were staged between unfamiliar pigs of the same treatment after 
weaning. Controlling for competitor weight difference revealed that increased play-fighting experience was linked to contest success in females, while the opposite pattern was found in males. Play-fighting experience did not influence which individual within the dyad escalated contest behaviour, but dyads containing more experienced losers were more likely to perform a stage of nondamaging aggression. When we used skin lesions in losers as a measure of contest cost, we found evidence for the role of play-fighting experience in a novel mutual assessment strategy in socialized dyads, whereas control dyads performed opponent-only assessment. We suggest that while assessments of RHP can be made using a physical correlate of play-fighting experience (such as skilfulness), early life socialization is required for individuals to gain an understanding of their own RHP.

\section{$\underline{\text { Key Words }}$}

aggression, assessment, contest, fighting ability, pig, play, resource-holding potential

The performance of fighting during animal contests is often costly to both winning and losing individuals in terms of energy, time and increased risk of predation, injury or mortality (Maynard Smith \& Price, 1973; Maynard Smith, 1974). Therefore, selection should favour individuals that are able to make tactical decisions based upon information gathered about the potential costs and benefits of continued conflict (Parker, 1974; Maynard Smith \& Parker, 1976; Parker \& Rubenstein, 1981). An individual's decision to either continue or withdraw from a contest is partly determined by its own fighting ability, commonly termed resource-holding potential (RHP; Parker, 1974). Typically, physical factors such as size or body weight are considered to indicate an animal's RHP as victory tends to go to the larger or heavier competitor (e.g. Austad, 1983; Stamps \& Krishnan, 1994; Draud \& Lynch, 2002). However, although an individual's size is generally correlated with its ability to inflict 
injuries upon its opponent (Archer, 1988), sometimes it is the smaller contestant that wins a conflict (see Neat et al., 1998; Hofmann et al., 2001), particularly if the size difference between competitors is small (Faber \& Baylis, 1993; Hughes, 1996). Previous research (reviewed by Arnott \& Elwood, 2009) has uncovered a range of additional physiological and behavioural factors that may additionally contribute to an individual's RHP, such as sex (Wilson, 1992), coloration (Stuart-Fox \& Johnston, 2005), previous contest experience (Zucker \& Murrary, 1996; Hsu \& Wolf, 1998) and even body temperature (Zamudio et al., 1995; Stutt \& Wilmer, 1998). However, one trait potentially influencing RHP that remains to be explored is early life social play experience.

Despite being observed in a variety of species, including mammals, birds, and potentially invertebrates (Fagen, 1981; Burghardt, 2005), the evolutionary function of play is still widely debated (Martin \& Caro, 1985; Špinka et al., 2001; Liebold et al., 2018). For a behaviour to be evolutionarily viable the fitness benefits of performing it must outweigh any associated fitness costs (Martin \& Caro, 1985), yet play is costly in both time and resources (Graham \& Burghardt, 2010; Held \& Špinka, 2011) and often does not appear fully functional (Bekoff, 1984; Burghardt, 2005). Therefore, it has continually been suggested that experiencing play early in life provides long-term benefits that increase overall fitness by some future means (Fagen, 1981; Martin \& Caro, 1985; Pellis et al., 2010; Cenni \& Fawcett, 2018), while being maintained in the short term by the sense of pleasure the performer receives (Trezza et al., 2010; Graham \& Burghardt, 2010). Several hypotheses related to this have been proposed, including the facilitation of motor performance and differentiation of skeletal muscle fibres (motor training hypothesis: Byers \& Walker, 1995), training both physically and cognitively for unexpected situations or temporary disorientation (training for the unexpected hypothesis: Špinka et al., 2001), and the development of social bonds and/or 
skills that will aid an individual later in life (social cohesion hypothesis: Bekoff, 1977, 1984, 2001).

Given the similarity between play-fighting behaviour and aggressive encounters later in life in some species (Fagen, 1981), it has repeatedly been suggested that early life social play may aid an individual's future fighting ability (Pellis, 1981; Jamieson \& Armitage, 1987; Watson \& Croft, 1993). Social play allows individuals to perform variations of adult interactions, such as fighting or mating, in an environment where transgressions from the accepted social norm are easily forgiven (Poirier \& Smith, 1974; Bekoff, 2001) and negative outcomes have little impact on social standing later in life. Consequently, these experiences provide a key opportunity for individuals to practise contest behaviours and improve the skill with which they can perform them (Smith, 1982; Briffa \& Lane, 2017). For example, play fighting in lions, Panthera leo, has been observed to improve from 'clumsy, pawing movements' to 'slaps or blows' (Schenkel, 1966) as individuals' experience of play increased. If play experience early in life contributes to an individual's RHP, it is reasonable to assume that it may contribute towards some of the previously reported deviations from predicted contest outcomes. Therefore, the role of play experience early in life on contest behaviour, and ultimately contest outcome, should be considered.

It has also been suggested that early life play allows individuals an opportunity to gather information regarding their own physical ability (Thompson, 1998). However, as a potential contributor to RHP, gathering information relating to the early life play experience of opponents, in the form of a correlated physical manifestation, may play an important role in assessment-informed contest decision making. While it is generally accepted that individuals will adjust their fighting strategy based on the perceived value of the disputed resource (Parker \& Stuart, 1976; Austad, 1983; Goubault et al., 2007; Arnott \& Elwood, 2008) the extent to which an individual can gather and use information relating to its own 
RHP and that of the opponent is still debated (Arnott \& Elwood, 2009; Elwood \& Arnott, 2012). Models developed to explore different assessment strategies can be broken into two main categories that differ fundamentally in their assumptions (Taylor \& Elwood, 2003).

Self-assessment models assume that individuals only have access to information regarding their own abilities and that no information is gathered about the quality of the opponent (e.g. 'War of attrition without assessment', Mesterton-Gibbons et al., 1996; 'Energetic war of attrition', Payne \& Pagel, 1996, 1997; 'Cumulative assessment model' (CAM), Payne, 1998). Individuals are predicted to persist in their performance of fighting behaviour until a maximum cost threshold, determined by the cost an individual is prepared to pay in order to win. Except under CAM (which predicts that opponents are able to inflict additional costs upon their opponent), individuals accrue these costs solely from the performance of their own actions and contests continue until the weaker rival reaches its maximum threshold. The second type of model involves mutual assessment (e.g. ‘Asymmetric war of attrition', Parker \& Rubenstein, 1981; Hammerstein \& Parker, 1982; 'Sequential assessment model' (SAM), Enquist \& Leimar, 1983; Enquist et al., 1990). In these strategies, contestants evaluate their own RHP relative to that of their opponent, enabling them to predict the most likely outcome of escalated conflict. As such, the weaker individual is able to terminate the conflict by retreating before further escalation, thus preventing additional contest costs being accrued unnecessarily. Under SAM, different levels of escalation are predicted to provide contestants with differing degrees of information about the opponent (Enquist \& Leimar 1983). However, while higher levels of escalation provide more accurate information, they are considered to be more costly (Koops \& Grant, 1993; Keeley \& Grant, 1993) and individuals that are better able to assess relative asymmetries in fighting ability should be selected for (Parker, 1974; Maynard Smith \& Parker, 1976). 

recently been debated (Elwood \& Arnott, 2012; Fawcett \& Mowles, 2013; Elwood \& Arnott, 2013), Taylor and Elwood (2003) have proposed a comprehensive framework for distinguishing alternative assessment strategies using the relationship between the RHP of competitors and costs acquired over the course of an aggressive encounter. Using this framework, we investigated whether preweaning play-fighting experience, translated into a physical manifestation through the skill with which individuals perform contest behaviours (Briffa \& Lane, 2017), is assessed as part of either a self- or a mutual assessment strategy. It is unlikely that individuals are able to make assessments based upon play-fighting experience itself, as an individual's ability to directly gather information regarding its own, or an opponent's, prior experiences is doubtful. Instead, increased play-fighting experience is likely to improve the skill with which individuals are able to perform the social behaviours required during an agonistic encounter (Briffa \& Lane, 2017). This translation of play experience into a physical trait would subsequently allow individuals to gather information on RHP (conferred by play-fighting experience) and make relative assessments. Additionally, in response to concerns over the validity of contest duration as a measure of contest cost (McGinley et al., 2015) multiple measures of temporal and physiological costs have been considered. Physiological measures of contest cost, that is, blood lactate and glucose levels before and after contests, have been validated for our study system (Camerlink et al., 2015; Camerlink et al. 2017). Additionally, this approach provides useful information on the energetic costs of contests (Briffa \& Elwood, 2005; Prenter et al., 2006).

Domestic pigs, Sus scrofa domestica, are a highly social species (Donaldson et al., 2002; Gieling et al., 2011) that rely on aggressive contests to establish new dominance relationships with unfamiliar individuals (Meese \& Ewbank, 1973). This is a considerable welfare issue for commercially raised pigs, as the mixing of unfamiliar individuals is a 
common practice (reviewed by Peden et al., 2018). However, previous studies have indicated that the socialization of piglets preweaning has a positive influence in terms of reducing costs of aggressive behaviour later in life (Wattanakl et al., 1997; D’Eath, 2005; Parratt et al., 2006; Kutzer et al., 2009; Verdon et al., 2016; Camerlink et al. 2018). Socialization represents a more ecologically relevant social environment for piglets, which would typically be introduced to unfamiliar individuals at 1-2 weeks of age (Newberry et al., 1986; Stobla \& Wood-Gush, 1989). Given that piglets are most playful at around 2-6 weeks of age (Newberry et al., 1988), and have a strong motivation to interact socially (Peterson et al., 1989), it is possible that preweaning socialization provides individuals with a more diverse range of social play experience (see Weller et al., 2019). In this study, therefore, we used preweaning socialization to maximize the variation in play experience subjects received.

We hypothesized that play experience early in life influences RHP, and can therefore be used to identify the assessment strategies adults use later in life. We first predicted that during agonistic encounters, the relative difference in competitors' preweaning social play experience will influence contest outcome later in life. Second, preweaning play-fighting experience was predicted to influence the escalation of contest behaviour at both the individual and dyadic level. Finally, individuals were predicted to use information regarding play-fighting experience as part of an assessment strategy.

\section{$\leq$ H1 $>$ Methods}

\section{$<$ H2>Ethical Note}

All procedures were carried out in accordance with the U.K. Government DEFRA animal welfare codes, the recommended European Guidelines for accommodation and care of animals, and the ASAB/ABS guidelines. Work was approved by SRUC's animal ethics committee (no. ED RP 04-2014) and the U.K. Government Home Office (project licence 
PPL60/4330) under the Animals Scientific Procedures Act 1986. All stages of the experiment were conducted in liaison with SRUC's veterinary surgeon.

\section{$<$ H2>Animals and Housing}

Our subjects were 263 piglets (138 males, 125 females) from 24 litters born to Large White x Landrace sows served by American Hampshire boars. Each sow contributed only one litter to the study. Piglets were born in two batches farrowed between January and February 2016 and were raised in conventional farrowing crate pens at the SRUC Easter Howgate pig unit (Roslin, U.K.). Farrowing pens were initially set at $21^{\circ} \mathrm{C}$ and were gradually reduced to $18{ }^{\circ} \mathrm{C}$ prior to weaning. Humidity ranged from approximately $60 \%$ to 70\%. Each pen contained a central sow crate and a solid front underfloor-heated creep area that was accessible via two entrances located on either side of the sow. Fresh straw and wood shavings were provided daily. Teeth and tails were kept intact, and males were not castrated. Piglets had access to water ad libitum from drinkers on the rear of the sow crate and received starter creep feed from day 21.

To create variation in the type and range of play behaviour experienced, six litters from each batch underwent a socialization treatment in which individuals were able to access a neighbouring pen, and subsequently nonlittermates, through a ca. $37 \times 74 \mathrm{~cm}$ opening in the pen partition from 14 days postpartum until weaning at 28 days of age. The six remaining litters per batch acted as controls and were kept within their home pens for the duration of lactation. Previously, socialization has shown no effect on play fighting or additional piglet directed play; however, socialized individuals directed approximately a third of this behaviour towards nonlittermates, indicating that these individuals experienced a more diverse range of play partners (Weller et al., 2019). 
At weaning, sows were removed from the farrowing crate while piglets were handled for tagging and vaccinations. Socialized litters were once again separated, and all litter groups were relocated to deep straw pens measuring 1.9 x $5.8 \mathrm{~m}$. Pens were cleaned and provided with fresh straw daily. Water and pelleted commercial feed were provided ad libitum. Once pigs had acclimatized to their new surroundings, each litter was gradually habituated to human contact. Pigs were also habituated to the test arena in diminishing group sizes until they were comfortable remaining alone in the test arena for $3 \mathrm{~min}$.

\section{$<$ H2>Measuring Play}

To assess the frequency of social play preweaning all pens were filmed between 1000 and 1600 hours on days 14, 16, 19, 21, 24 and 26 using Geovision surveillance hardware linked to GV-1480 playback software (GeoVision Inc., Taiwan). Cameras were installed above each individual pen and provided a clear view of the open areas. Video footage of the inside of the heated creep was not available. Recordings from these cameras were played back using EZViewLog500 and coded for behaviours using a clearly validated ethogram (Weller et al., 2019; Appendix Table A1) that captured frequencies of play fighting. All observations were made by a single observer. Pigs were identified in video recordings from back numbers applied with an animal marker spray.

Any instances of play fighting occurring within the first 15 min of every hour were recorded for each piglet within a pen simultaneously. The play experience of piglets from the socialized treatment was scored in both pens separately before being summed. From this, total play-fighting experience (all successful play-fighting invites made in addition to all accepted play-fighting invites received) was calculated.

\section{$<H 2>$ Contests}



their suitability for testing (i.e. weight and body condition) and paired with either a weightmatched ( $<6 \%$ weight difference) or weight-unmatched ( $>14 \%$ weight difference) unfamiliar individual from the same treatment group. This resulted in the formation of 76 dyads (socialized: 46; control: 30 ). allowed both opponents to enter simultaneously from holding pens on opposite sides. Contests began once the competitors had fully entered the arena and were ended a maximum of 1 min after either individual performed retreat behaviour (hereafter referred to as the loser), providing that no retaliation attack was made. Contest duration was calculated as the time between the start of the contest and a successful retreat. Contests were also ended if no clear winner was observed within 20 min of individuals entering the pen. Contestants were than superficial skill lesions, if one pig experienced repeated mounting (more than five mounts or before the mounted individual became distressed), or if either individual displayed repeated fear behaviours (i.e. sustained distress vocalizations for over $1 \mathrm{~min}$, more than three attempted escape climbs or a single attempted escape jump).

\section{$<$ H2>Measuring Contest Costs}

The performance of intermittent stages of contest behaviour (display, nondamaging aggression, biting and mutual fighting; Appendix Table A2) was also recorded to explore the effect of play-fighting experience on contest escalation. In addition to live observations, contests were recorded using a Canon Legria HFS21 camcorder set at standard definition with a wide-angle lens, positioned $5 \mathrm{~m}$ above the contest arena at a 30-degree angle. Videos were then played back in Noldus Observer XT10 (Noldus Information Technology, 
Wageninegen, The Netherlands) to calculate the duration of mutual fighting. Both winner and loser skin lesions were counted directly before and after contests to assess the intensity of fighting. We considered skin lesions to be scratches located anywhere on the body resulting from being bitten by the opponent.

To quantify physiological measures of contest cost, a small drop of blood was collected both immediately before and after the contests. Pigs were habituated to ear touching and handling in the sampling crate over a period of 2 weeks. Blood was obtained by an experienced technician pricking the ear vein with a flat-bladed capillary blood lancet. The sample was then directly applied to test strips of a blood glucose meter (iDia Blood Glucose Meter, IME-DC GmbH, Hof, Germany) and a blood lactate meter (The EDGE Lactate Analyser, Woodley Equipment, Bolton, U.K.). Owing to range limitations with the lactate meter (0.7-22.2 mmol/litre) two individuals were reported to be below the minimum blood lactate threshold precontest and were thus given the minimum reading of $0.7 \mathrm{mmol} / \mathrm{litre}$. Additionally, another individual was reported to be above the maximum threshold postcontest and was subsequently given the maximum reading of $22.2 \mathrm{mmol} / \mathrm{litre}$. The proportional change in winner and loser blood lactate/glucose was calculated as the postcontest concentration divided by the concentration recorded precontest. Thus, eight measures of contest cost were recorded; contest duration, duration of mutual fighting, winner skin lesions, loser skin lesions and proportional increase in winner blood glucose, loser blood glucose, winner blood lactate and loser blood lactate.

\section{$<$ H2>Statistical Analysis}

All data analyses were performed using the statistical package $\mathrm{R}$ version 3.4.0 (The $\mathrm{R}$ Foundation for Statistical Computing, Vienna, Austria). Data are presented as the mean \pm SEM. Owing to technical difficulties, play behaviour data were not obtainable for one of the 
control groups and subsequently dyads including these individuals were removed from the analyses. Furthermore, in addition to the four contests ended by researchers, three dyads had no clear winner within the 20 min time limit. This resulted in a total sample size of 65 dyads, of which 34 were matched for weight. Fifty-two dyads were examined for mutual fighting duration (as the remaining contests did not escalate to mutual fighting), and skin lesion counts and glucose/lactate blood sampling were performed for a total of 130 pigs (65 winners/65 losers).

Owing to its binary nature, contest outcome was explored using generalized linear mixed-effects models following a binomial distribution with a logit link function. Competitor difference in preweaning play-fighting experience, difference in competitor body weight and the sex of the focal individual were included in the model as fixed effects, while batch, litter and dyad ID were included as nested random effects to account for nonindependence of opponents (Briffa \& Elwood, 2010). Models initially included all relevant variables and interactions, which were removed from the model using a top-down approach to find the best fitting model, as indicated by the Akaike information criterion (AIC scoring). Test statistics were then extracted using a Wald's test.

A series of three separate factorial ANOVAs, with winner play, loser play and combined play-fighting experience of dyads as the response variables and the performance of display, nondamaging aggression and mutual fighting as explanatory factors with two levels (performance/no performance) were used to examine whether play-fighting experience differed with contest escalation. Biting was not included in this analysis as only one dyad did not perform the behaviour.

To explore escalation behaviour within a dyad, the preweaning play-fighting experience of the individual initiating escalation was compared to that of the recipient 
individual using a paired $t$ test for each escalation stage. In each case, the difference between both individuals was checked for normality using a Shapiro-Wilk test and data were log transformed as required. The role of play-fighting experience as part of an assessment strategy was explored using eight separate general linear mixed-effects models each including one of the eight measures of contest cost as the dependent variable. Each model contained winner play-fighting experience, loser play-fighting experience and treatment (socialized or control) as fixed effects, while batch was included as a random factor. Model residuals were examined for normality (using QQ-plots) and contest costs were log transformed or square-root transformed accordingly when required. Models initially included all relevant variables and interactions, which were then removed from the model in the same manner as before. Models were examined for fit using maximum likelihood and the best fitting model (as indicated by AIC scores) was examined by means of a Wald's test using restricted maximum likelihood. To further explore whether individuals use information regarding play-fighting experience as part of a self- or mutual assessment strategy, the standardized beta coefficients $(\beta)$ of winner or loser play-fighting experience effects on contest costs were calculated using linear regressions.

\section{$\leq$ H1 $>$ Results}

In total, three contests ended in a time out, with no clear winner being identified. A further two contests were ended due to repeated mounting, one contest was ended due to escape attempts and one contest was ended due to health concerns.

\section{$<$ H2>Contest Outcome}

Exploration of the effect of preweaning play-fighting experience on contest outcome revealed that only the difference in competitor weight significantly influenced outcome, with the heavier individual within the dyad being the most likely to win the contest $\left(\chi^{2}{ }_{1}=6.219\right.$, 
$P=0.013$; Fig. 1). However, play-fighting experience was positively correlated with body weight (Spearman rank correlation: $r_{\mathrm{S}}=0.207, N=130, P=0.018$ ). To account for associations between weight and play, the play-fighting experience of weight-matched dyads $(N=34$ dyads) was investigated using a similar generalized linear mixed-effects model that did not include competitor weight difference as an explanatory factor. While neither play-fighting experience $\left(\chi^{2}{ }_{1}=0.004, P=0.950\right)$ nor $\operatorname{sex}\left(\chi^{2}{ }_{1}=1.721, P=0.190\right)$ individually influenced contest outcome, there was a significant interaction effect between the two $\left(\chi^{2}{ }_{1}=3.869\right.$, $P=0.049)$. Female winners experienced more play fighting pre-weaning $(22.06 \pm 2.77)$ than losing females $(18.23 \pm 2.86$; Cohen's $d=0.31)$, while male winners had experienced less play fighting preweaning $(29.50 \pm 3.49)$ than losing males $(38.08 \pm 6.83$; Cohen's $d=0.43$; Fig. 2).

\section{$<$ H2>Contest Escalation}

Regarding contest escalation, dyads that performed non-damaging aggression had a significantly higher combined pre-weaning play-fighting experience than dyads that did not (Table 1, Fig. 3). Inclusion of nondamaging aggression appeared to be primarily the result of increased loser play-fighting experience (Table 1), as winner play fighting did not differ significantly between dyads that performed this phase and those that did not (Table 1).

The performance of other levels of escalation were not significantly influenced by winner, loser or combined play-fighting experience (Table 1), although there was a trend for dyads containing more playful losers to perform mutual fighting behaviour (Table 1).

Furthermore, the escalation of behaviour within a contest was equally likely to be initiated by either competitor, regardless of preweaning play-fighting experience (Table 2).

\section{$<$ H2>Contest Cost}



spending ca. $1 \frac{1}{2} 2 \min (81.90 \pm 15.82 \mathrm{~s})$ performing mutual fighting. Neither winner nor loser play-fighting experience influenced contest duration $(P>0.05)$, although contests between socialized pigs were significantly shorter $(185 \pm 28$ s) than those between control pigs $(290 \pm$ $\left.49 \mathrm{~s} ; \chi^{2}{ }_{1}=4.277, P=0.039\right)$. The duration of mutual fighting was not significantly affected by treatment group (socialized: $68 \pm 18 \mathrm{~s}$; control: $108 \pm 30 \mathrm{~s}$ ), winner play-fighting experience or loser play-fighting experience (all $P>0.05$ ).

\section{$\leq$ H3>Skin Lesions and Physiological Costs}

The number of skin lesions a winning individual received during contests was significantly affected by treatment $\left(\chi^{2}{ }_{1}=3.843, P=0.05\right)$, with winners from the socialized treatment receiving fewer skin lesions $(30.76 \pm 6.00)$ than winners from control dyads $(50.35$ \pm 9.78 ). Furthermore, regarding loser skin lesions, we found a three-way interaction between winner play-fighting experience, loser play-fighting experience and treatment $\left(\chi_{1}^{2}=5.068\right.$, $P=0.024)$. Within socialized dyads, loser skin lesions were positively related to winner playfighting experience and negatively related to loser play-fighting experience. On the other hand, within the control dyads winner play-fighting experience was negatively related to the number of skin lesions the loser received, with a weaker negative relationship for the loser (Table 3, Fig. 4).

Prior to contests the mean blood glucose value was $6.02 \pm 0.08 \mathrm{mmol} /$ litre (range 2.59.7) while the mean blood lactate value was $1.93 \pm 0.06 \mathrm{mmol} /$ litre (range 0.7-4.0). After contests, mean blood glucose increased to $7.01 \pm 0.12 \mathrm{mmol} /$ litre (range 4.6-11.6) and lactate to $8.08 \pm 0.45 \mathrm{mmol} /$ litre (range 1.1-22.1). Winners and losers did not differ significantly in proportional change in blood glucose (Wilcoxon signed- rank test: $W=2302.5, N=130$ individuals, $P=0.377$ ) or lactate (paired $t$ test: $t_{124.29}=-0.299, P=0.766$ ). Treatment, winner 
play-fighting experience and loser play-fighting experience did not influence proportional increase in winner blood lactate, winner blood glucose or loser blood lactate. The proportional increase in loser blood glucose was significantly influenced by a three-way interaction between winner play, loser play and treatment $\left(\chi^{2}{ }_{1}=5.068, P=0.024\right)$. However, this revealed only very weak positive relationships (Table 3) between winner and loser playfighting experience and loser blood glucose, not consistent with any form of assessment.

\section{$\leq$ H1 $>$ Discussion}

We had hypothesized that play experience early in life influences an individual's RHP later in life. As predicted, contest outcome was significantly influenced by play-fighting experience, although this was only the case in females, suggesting that play-fighting experience is a component of RHP in female pigs. Additionally, we had predicted that play experience would influence the escalation of contest behaviour at both an individual and a dyadic level. Contrary to this, however, the initiator and recipient individuals within a dyad did not differ in their preweaning play-fighting experience. However, at a dyadic level, those performing a stage of nondamaging aggression included losers with higher levels of early life play experience (and subsequently a higher combined play-fighting experience) than dyads that did not. Regarding our third hypothesis, the assessment of play-fighting experience was examined by investigating relationships between winner and loser play experience and a range of contest costs. Results for loser skin lesions revealed intriguing evidence of assessment that differed between socialized and control dyads.

\section{$<H 2>$ Play-fighting experience as a component of RHP}

As has previously been observed (Camerlink et al., 2017), differences in competitor weight significantly influenced contest outcome, with the heavier individuals being more likely to win a contest than their opponent. However, the current study revealed a correlation 
between preweaning play fighting and body weight, supporting previous findings that suggest an underlying link between early life growth and play experience (Brown et al., 2015). As play is considered a luxury behaviour that individuals perform only when all other needs have been fulfilled (Martin \& Caro, 1985; Newberry et al., 1988; Horback, 2014, Brown et al., 2015), it is likely that individuals able to gain the most weight preweaning are also those that can afford to perform the most social play.

When matched for body weight, differences in competitor play-fighting experience were found to interact significantly with sex to influence contest outcome. While female winners were observed to have performed more play fighting than female losers, male winners were found to have experienced less play fighting preweaning than losers. One possible explanation for this sex-dependent result is the dimorphism observed in the social behaviour of males and females later in life. Under free-ranging conditions, female wild boar live in hierarchical family units referred to as sounders (Tisdell, 1982; Gabor et al., 1999). Dominance relationships within these units are typically weakly enforced, with brief periods of social instability coinciding with the final stages of pregnancy and the weaning of piglets (Kaminski et al., 2005). Given the relatedness of nearby females, in addition to the frequent re-formation of the dominance hierarchy, the fitness cost of losing an agonistic encounter is likely to be relatively low in females. Males, on the other hand, are normally solitary outside of breeding (Tisdell, 1982, Barrette, 1986, Gabor et al., 1999), when they will vigorously compete for access to sounders (Tisdell, 1982). As males are able to sire multiple litters at a time, the reproductive benefits of winning a contest are considerably higher in males than in females. Therefore, males may be prepared to engage in more damaging behaviours than those performed during early life play. Furthermore, during agonistic encounters, males will attempt to slash one another using sharp tusks (Kurz \& Marchinton, 1972; Signoret et al., 1975; Barrette, 1986). While piglets are born with sharp temporary canine teeth (Signoret et 
al., 1975) the development of large tusks in adult males is likely to cause a large disparity between play fighting and the aggressive behaviours performed later in life. This suggests that the benefits associated with increased play experience are likely to depend on an individual's sex, given the sexual dimorphism observed in the adult social environment of males and females, (Meaney et al., 1985, Burghardt, 2005; Cameron et al., 2008; but see Pellis et al., 1997). In the case of domestic pigs, early life play experience appears beneficial in females, but to negatively impact male contest outcome. However, given the evolutionary persistence of social play in males, this result suggests males gain an alternative benefit from the performance of this behaviour, such as the development of skeletal muscle (Byers \& Walker, 1995) or gaining experience in responding to unexpected situations (Špinka et al., 2001). It is also important to consider the age of pigs during these staged contests; under natural conditions male pigs of this age would still be with their maternal sounder (Newberry \& Wood-Gush, 1985). As such, the benefits of early life play in males may not be observed until they have reached sexual maturity.

Early life play-fighting experience has commonly been assumed to influence the performance of adult aggressive behaviours (Pellis, 1981; Jamieson \& Armitage, 1987; Rothstein \& Griswold, 1991; Watson \& Croff, 1993; Petit et al., 2008), although investigation into the effect of play on contest dynamics has been limited and at times contradictory. Blumstein et al. (2013) observed that young yellow-bellied marmots, Marmota flaviventris, that were socially dominant within the context of play held higher dominance positions as indicated by contest outcome later in life. Conversely, a study in meerkats, Suricata suricatta, found that the frequency of juvenile play fighting did not influence the outcome of agonistic interactions later in life (Sharpe, 2005). Furthermore, the frequency of social play did not affect the ability of young meerkats to obtain a dominant wrestling position during agonistic encounters. Our study provides new evidence to suggest that early 
life play-fighting experience can contribute to an individual's RHP, and subsequently can increase or decrease an individual's likelihood of success during agonistic encounters later in life in a sex-dependent way.

\section{$<$ H2>Effect of Play-fighting experience on Contest Behaviour and Escalation}

Contrary to our predictions, play-fighting experience did not predict which individual within the dyad escalated contest behaviour at any stage of the agonistic encounter. However, dyads that performed an additional stage of nondamaging aggression before escalation to mutual fighting had a significantly higher total play experience, and specifically a more experienced losing individual, than dyads that did not. Given that the cost of contests is governed by the RHP of the loser (Arnott \& Elwood, 2009), and that dyads containing losing individuals with high play-fighting experience were more likely to escalate contests to later stages of aggression, these results further support the hypothesis that preweaning playfighting experience acts as a component of individual RHP. Furthermore, the performance of nondamaging aggression before the escalation of contests to mutual fighting may allow competitors to reach a conclusion regarding contest outcome without the need to perform highly damaging behaviour, such as mutual fighting. Increased early life play-fighting experience may facilitate the performance of nondamaging aggression as it allows individuals to practise the performance of these contest behaviours in a relatively safe environment (Essler et al., 2016). However, while it can be hypothesized that increasing play fighting allows for the development and practice of a wider range of contest behaviours, the possibility that both behaviours are mediated by some common personality aspect, such as boldness, should be considered.

\section{$<$ H2>Assessment of Play-fighting experience}



this study found evidence to suggest that play-fighting experience (probably manifested as a physical trait such as skill; sensu Briffa \& Lane 2017) is used as part of an assessment strategy. Owing to previous concerns regarding the validity of using contest duration as a proxy for cost (McGinley et al., 2015; Camerlink et al., 2015; Camerlink et al., 2017), we also explored the duration of mutual fighting and four additional physiological indicators of contest cost, in addition to the number of skin lesions individuals received during the contest. Loser skin lesions were influenced by a three-way interaction effect including winner playfighting experience, loser play-fighting experience and treatment. Within the socialized treatment, the number of skin lesions a loser received increased as the play-fighting experience of the winner increased. Additionally, loser skin lesions decreased with increasing loser play-fighting experience. This finding is consistent with a novel form of mutual assessment in which the motivation to fight (revealed through examination of contest cost) of

$$
\text { winner RHP. Despite being the opposite of the original predictions for mutual assessment it is }
$$
consistent with the findings of other recent studies (Kareklas et al. 2019; Camerlink et al. 2019).

Initially the engagement of more formidable individuals seems counterintuitive; however, challenging a superior opponent may have its advantages, as revealed by a number of contest models (Grafen, 1987; Just \& Morris, 2003; Morrell et al., 2005). Grafen (1987) suggested a 'desperado effect', in which individuals with a prior history of losing will disregard asymmetries in RHP between themselves and their opponent when the value they place upon a disputed resource is high. Furthermore, the Napoleon strategy demonstrates that if fight outcome is not solely predicted by RHP then small individuals can be as aggressive as their larger opponents (Morrell et al., 2005). In the current study it is particularly intriguing 
that this novel form of assessment was only observed in socialized and not control dyads.

Within the control treatment loser skin lesions decreased with increasing winner play-fighting experience. Individuals appeared to be less motivated to continue fighting (and sustain further costs) if their opponent demonstrated high play-fighting experience, manifested through some physical correlate (e.g. skill; Briffa \& Lane 2017). On the other hand, loser skin lesions were largely unaffected by loser play-fighting experience, indicating that individuals did not consider their own play-fighting experience and suggesting a form of opponent-only assessment (Arnott \& Elwood 2009; Elwood \& Arnott 2012). These findings suggest that socialized individuals had an increased confidence in their own fighting ability, potentially owing to their prior experiences with non-littermates, resulting in the expression of elevated aggressive intent towards opponents with a higher RHP. This is in line with the findings of several previous studies that showed socialized individuals were quicker than control individuals to attack a clearly subordinate animal during resident-intruder testing (D’Eath, 2005; Weller et al., 2019).

Alternatively, it should be considered that while socialization does not increase playfighting experience (Weller et al., 2019), having access to nonlitter mates within the socialized treatment may have improved the skill with which individuals performed contest behaviour. Winners from the socialization treatment that experienced high levels of play fighting may have been better able to inflict skin lesions upon the loser than winners from the control treatment, while increased play-fighting experience in the socialized loser may have resulted in them being better able to avoid being bitten than their control counterparts. Therefore, a potentially fruitful avenue of future research will be to explore how early life experience, including play, influences the performance of skills required in a contest setting, such as deflecting an opponent or delivering a bite (Briffa \& Lane 2017). 
While there was a three-way interaction between winner play-fighting experience,

loser play-fighting experience and treatment on the proportional increase in loser blood glucose, this revealed only weak positive relationships not consistent with any form of assessment. Previously, Camerlink et al. (2015) reported that while blood lactate increased with contest duration, substituting contest duration with blood lactate revealed no evidence for assessment and that there was no significant relationship between blood lactate and aggressiveness or body weight. This highlights the importance of considering multiple measures of contest cost when exploring contest assessment strategies unless a fully encompassing measure of contest cost can be identified.

\section{$\leq \mathbf{H} 2>$ Conclusion}

When body weight was accounted for, contest outcome was influenced by preweaning play-fighting experience, with female winners having more experience than female losers and male winners having less experience than male losers. This suggests that preweaning playfighting experience serves as a component of RHP, with the extent of its influence being related to sex. Although play-fighting experience did not influence which individual within the dyad escalated contest behaviour, dyads that performed an additional stage of nondamaging aggression were found to have higher combined play-fighting experience and more experienced losers than dyads that did not, indicating that play experience is likely to aid in the development of contest behaviours. Lastly, evidence was found to suggest that play-fighting experience (in terms of a physically manifested correlate) could be assessed as part of a novel mutual assessment strategy in dyads that had experienced preweaning socialization. These findings suggest that early life social play in the domestic pig is an important predictor of contest success later in life and can reduce escalated aggression during agonistic encounters. As such, the social play experience of commercially reared pigs should 
537 juvenile welfare.

538

\section{Acknowledgments}

\section{$\underline{\text { References }}$}

This research was funded by the Biotechnology and Biological Sciences Research Council (BBSRC) grant BB/L000393/1.

Arnott, G., \& Elwood, R. W. (2008). Information gathering and decision making about resource value in animal contests. Animal Behaviour, 76(3), 529-542. https://doi.org/10.1016/j.anbehav.2008.04.019

Arnott, G., \& Elwood, R. W. (2009). Assessment of fighting ability in animal contests. Animal Behaviour, 77(5), 991-1004. https://doi.org/10.1016/j.anbehav.2009.02.010 Archer, J. (1988). The Behavioural Biology of Aggression. Cambridge, U.K.: Cambridge University Press.

Austad, S. N. (1983). A game theoretical interpretation of male combat in the bowl and doily spider (Frontinella pyramitela). Animal Behaviour, 31(1), 59-73. https://doi.org/10.1016/S0003-3472(83)80173-0

Barrette, C. (1986). Fighting behavior of wild Sus scrofa. Journal of Mammalogy, 67(1), 177-179. https://doi.org/10.2307/1381018

Bekoff, M. (1977). Mammalian dispersal and the ontogeny of individual behavioral phenotypes. The American Naturalist, 111(980), 715-732. https://doi.org/10.1086/283201 
Bekoff, M. (1984). Social play behavior. Bioscience, 34(4), 228-233.

559

560

561

562

563

564

565

566

567

568

569

570

571

572

573

574

575

576

577

578

579

580

\section{https://doi.org/10.2307/1309460}

Bekoff, M. (2001). Social play behaviour. Cooperation, fairness, trust, and the evolution of morality. Journal of Consciousness Studies, 8(2), 81-90.

https://www.ingentaconnect.com/content/imp/jcs/2001/00000008/00000002/1075

Blumstein, D. T., Chung, L. K., \& Smith, J. E. (2013). Early play may predict later dominance relationships in yellow-bellied marmots (Marmota flaviventris). Proceedings of the Royal Society B: Biological Sciences, 280(1759), 20130485. https://doi.org/10.1098/rspb.2013.0485

Briffa, M., \& Elwood, R. W. (2005). Rapid change in energy status in fighting animals: causes and effects of strategic decisions. Animal Behaviour, 70(1), 119-124.

https://doi.org/10.1016/j.anbehav.2004.10.013

Briffa, M., \& Elwood, R. W. (2010). Repeated measures analysis of contests and other dyadic interactions: problems of semantics, not statistical validity. Animal Behaviour, 80(3), 583-588. https://doi.org/10.1016/j.anbehav.2010.06.009

Briffa, M., \& Lane, S. M. (2017). The role of skill in animal contests: a neglected component of fighting ability. Proceedings of the Royal Society B: Biological Sciences, 284(1863), 20171596. https://doi.org/10.1098/rspb.2017.1596

Brown, S. M., Klaffenböck, M., Nevison, I. M., \& Lawrence, A. B. (2015). Evidence for litter differences in play behaviour in pre-weaned pigs. Applied animal behaviour science, 172, 17-25. https://doi.org/10.1016/j.applanim.2015.09.007

Burghardt, G.M. (2005). The genesis of animal play: Testing the limits. Cambridge, MA: The MIT Press. 
Byers, J. A., \& Walker, C. (1995). Refining the motor training hypothesis for the

582

583

584

585

586

587

588

589

590

591

592

593

594

595

596

597

598

599

600

601

602

603 evolution of play. The American Naturalist, 146(1), 25-40. https://doi.org/10.1086/285785

Camerlink, I., Turner, S. P., Farish, M., \& Arnott, G. (2015). Aggressiveness as a component of fighting ability in pigs using a game-theoretical framework. Animal Behaviour, 108, 183-191. https://doi.org/10.1016/j.anbehav.2015.07.032

Camerlink, I., Arnott, G., Farish, M., \& Turner, S. P. (2016). Complex contests and the influence of aggressiveness in pigs. Animal Behaviour, 121, 71-78. https://doi.org/10.1016/j.anbehav.2016.08.021

Camerlink, I., Turner, S. P., Farish, M., \& Arnott, G. (2017). The influence of experience on contest assessment strategies. Scientific Reports, 7(1), 14492. https://doi.org/10.1038/s41598-017-15144-8

Camerlink, I., Farish, M., D’Eath, R., Arnott, G., \& Turner, S. (2018). Long Term Benefits on Social Behaviour after Early Life Socialization of Piglets. Animals, 8(11), 192. https://doi.org/10.3390/ani8110192

Camerlink, I., Turner, S. P., Farish, M., \& Arnott, G. (2019). Advantages of social skills for contest resolution. Royal Society Open Science, 6(5), 181456. https://doi.org/10.1098/rsos.181456

Cameron, E. Z., Linklater, W. L., Stafford, K. J., \& Minot, E. O. (2008). Maternal investment results in better foal condition through increased play behaviour in horses. Animal Behaviour, 76(5), 1511-1518. https://doi.org/10.1016/j.anbehav.2008.07.009 Cenni, C., \& Fawcett, T. W. (2018). The coevolution of juvenile play-fighting and adult competition. Ethology, 124(5), 290-301. https://doi.org/10.1111/eth.12732 
604

605

606

607

608

609

610

611

612

613

614

615

616

617

618

619

620

621

622

623

624

625

D’Eath, R. B. (2005). Socialising piglets before weaning improves social hierarchy formation when pigs are mixed post-weaning. Applied Animal Behaviour Science, 93(34), 199-211. https://doi.org/10.1016/j.applanim.2004.11.019

Donaldson, T. M., Newberry, R. C., Špinka, M., \& Cloutier, S. (2002). Effects of early play experience on play behaviour of piglets after weaning. Applied Animal Behaviour Science, 79(3), 221-231. https://doi.org/10.1016/S0168-1591(02)00138-7

Draud, M., \& Lynch, P. A. (2002). Asymmetric contests for breeding sites between monogamous pairs of convict cichlids (Archocentrus nigrofasciatum, Cichlidae): pair experience pays. Behaviour, 139(7), 861-874.

https://doi.org/10.1163/156853902320387864

Elwood, R. W., \& Arnott, G. (2012). Understanding how animals fight with Lloyd Morgan's canon. Animal Behaviour, 84(5), 1095-1102.

https://doi.org/10.1016/j.anbehav.2012.08.035

Elwood, R. W., \& Arnott, G. (2013). Assessments in contests are frequently assumed to be complex when simple explanations will suffice. Animal Behaviour, 86(5), e8-e12. https://doi.org/10.1016/j.anbehav.2013.09.006

Enquist, M., \& Leimar, O. (1983). Evolution of fighting behaviour: decision rules and assessment of relative strength. Journal of theoretical Biology, 102(3), 387-410. https://doi.org/10.1016/0022-5193(83)90376-4

Enquist, M., Leimar, O., Ljungberg, T., Mallner, Y., \& Segerdahl, N. (1990). A test of the sequential assessment game: fighting in the cichlid fish Nannacara anomala. Animal Behaviour, 40(1), 1-14. https://doi.org/10.1016/S0003-3472(05)80660-8 
Essler, J. L., Cafazzo, S., Marshall-Pescini, S., Virányi, Z., Kotrschal, K., \& Range, F. (2016). Play behavior in wolves: Using the '50: 50'rule to test for egalitarian play styles. PloS One, 11(5), e0154150. https://doi.org/10.1371/journal.pone.0154150

Faber, D.B. and Baylis, J.R., 1993. Effects of body size on agonistic encounters between male jumping spiders (Araneae: Salticidae). Animal Behaviour, 45(2), pp.289-299. https://doi.org/10.1006/anbe.1993.1033

Fagen, R. (1981). Animal play behavior. New York, NY: Oxford University Press Fawcett, T. W., \& Mowles, S. L. (2013). Assessments of fighting ability need not be cognitively complex. Animal Behaviour, 5(86), pp.e1-e7. https://doi.org/10.1016/j.anbehav.2013.05.033

Gabor, T. M., Hellgren, E. C., Van Den Bussche, R. A., \& Silvy, N. J. (1999).

Demography, sociospatial behaviour and genetics of feral pigs (Sus scrofa) in a semi-arid environment. Journal of Zoology, 247(3), 311-322. https://doi.org/10.1111/j.14697998.1999.tb00994.x

Gieling, E. T., Nordquist, R. E., \& van der Staay, F. J. (2011). Assessing learning and memory in pigs. Animal cognition, 14(2), 151-173. https://doi.org/10.1007/s10071-0100364-3

Goubault, M., Scott, D., \& Hardy, I. C. (2007). The importance of offspring value: maternal defence in parasitoid contests. Animal Behaviour, 74(3), 437-446. https://doi.org/10.1016/j.anbehav.2006.11.029

Grafen, A. (1987). The logic of divisively asymmetric contests: respect for ownership and the desperado effect. Animal Behaviour, 35(2), 462-467. https://doi.org/10.1016/S00033472(87)80271-3 
Graham, K. L., \& Burghardt, G. M. (2010). Current perspectives on the biological study

650

651

652

653

654

655

656

657

658

659

660

661

662

663

664

665

666

667

668

669

670 of play: signs of progress. The Quarterly Review of Biology, 85(4), 393-418.

https://doi.org/10.1086/656903

Hammerstein, P., \& Parker, G. A. (1982). The asymmetric war of attrition. Journal of Theoretical Biology, 96(4), 647-682. https://doi.org/10.1016/0022-5193(82)90235-1

Held, S. D., \& Špinka, M. (2011). Animal play and animal welfare. Animal Behaviour, 81(5), 891-899. https://doi.org/10.1016/j.anbehav.2011.01.007

Hofmann, H. A., \& Schildberger, K. (2001). Assessment of strength and willingness to fight during aggressive encounters in crickets. Animal Behaviour, 62(2), 337-348. https://doi.org/10.1006/anbe.2001.1746

Horback, K. (2014). Nosing around: Play in pigs. Animal Behavior and Cognition, 1(2), pp.186-196. http://doi.org/10.12966/abc.05.08.2014

Hsu, Y., \& Wolf, L. L. (1999). The winner and loser effect: integrating multiple experiences. Animal Behaviour, 57(4), 903-910. https://doi.org/10.1006/anbe.1998.1049 Hughes, M. (1996). Size assessment via a visual signal in snapping shrimp. Behavioral Ecology and Sociobiology, 38(1), 51-57. https://doi.org/10.1007/s002650050216

Jamieson, S. H., \& Armitage, K. B. (1987). Sex differences in the play behavior of yearling yellow-bellied marmots. Ethology, 74(3), 237-253.

https://doi.org/10.1111/j.1439-0310.1987.tb00936.x

Just, W., \& Morris, M. R. (2003). The Napoleon complex: why smaller males pick fights. Evolutionary Ecology, 17(5-6), 509-522.

https://doi.org/10.1023/B:EVEC.0000005629.54152.83 

female wild boars (Sus scrofa): mother-daughter postweaning associations. Canadian Journal of Zoology, 83(3), 474-480. https://doi.org/10.1139/z05-019

Kareklas, K., McMurray, R., \& Arnott, G. (2019). Increased aggressive motivation towards formidable opponents: evidence of a novel form of mutual assessment. Animal Behaviour, 153, 33-40. https://doi.org/10.1016/j.anbehav.2019.04.013

Keeley, E. R., \& Grant, J. W. (1993). Visual information, resource value, and sequential assessment in convict cichlid (Cichlasoma nigrofasciatum) contests. Behavioral Ecology, https://doi.org/10.1139/z93-068

Kurz, J. C., \& Marchinton, R. L. (1972). Radiotelemetry studies of feral hogs in South Carolina. The Journal of Wildlife Management, 1240-1248. https://doi.org/10.2307/3799254

Kutzer, T., Bünger, B., Kjaer, J. B., \& Schrader, L. (2009). Effects of early contact between non-littermate piglets and of the complexity of farrowing conditions on social behaviour and weight gain. Applied Animal Behaviour Science, 121(1), 16-24. https://doi.org/10.1016/j.applanim.2009.08.004

Liebold, B., Koban, K. \& Ohler, P. (2018). Evolution of Play: Playing Digital Games between Biological Imperatives and a Pretend Mode of Thinking in B.J., Pietschmann. D., Liebold, B., \& Larige, B.P., (ed.) Evolutionary Psychology and digital games.(pp. 1531). New York, NY: Routledge. 
Martin, P., \& Caro, T. M. (1985). On the functions of play and its role in behavioral

695

696

697

698

699

700

701

702

703

704

705

706

707

708

709

710

711

712 development. Advances in the Study of Behavior ,15, 59-103).

https://doi.org/10.1016/S0065-3454(08)60487-8

Maynard Smith, J. (1974). The theory of games and the evolution of animal conflicts. Journal of theoretical biology, 47(1), 209-221. https://doi.org/10.1016/00225193(74)90110-6

Maynard Smith, J., \& Parker, G. A. (1976). The logic of asymmetric contests. Animal Behaviour, 24(1), 159-175. https://doi.org/10.1016/S0003-3472(76)80110-8

Maynard Smith, J. \& Price, G.R. (1973). The logic of animal conflict. Nature, 246(5427), 15. https://doi.org/10.1038/246015a0

McGinley, R. H., Prenter, J., \& Taylor, P. W. (2015). Assessment strategies and decision making in male-male contests of Servaea incana jumping spiders. Animal Behaviour, 101, 89-95. https://doi.org/10.1016/j.anbehav.2014.12.014

Meaney, M. J., Stewart, J., \& Beatty, W. W. (1985). Sex differences in social play: The socialization of sex roles. Advances in the Study of Behavior, 15, 1-58. https://doi.org/10.1016/S0065-3454(08)60486-6

Meese, G. B., \& Ewbank, R. (1973). The establishment and nature of the dominance hierarchy in the domesticated pig. Animal Behaviour, 21(2), 326-334. https://doi.org/10.1016/S0003-3472(73)80074-0

Mesterton-Gibbons, M., Marden, J. H., \& Dugatkin, L. A. (1996). On wars of attrition without assessment. Journal of theoretical Biology, 181(1), 65-83.

https://doi.org/10.1006/jtbi.1996.0115 
Morrell, L. J., Lindström, J., \& Ruxton, G. D. (2005). Why are small males aggressive?

Neat, F. C., Huntingford, F. A., \& Beveridge, M. M. (1998). Fighting and assessment in male cichlid fish: the effects of asymmetries in gonadal state and body size. Animal Behaviour, 55(4), 883-891. https://doi.org/10.1006/anbe.1997.0669 in a semi-natural environment. Behaviour, 95(1), 1-25. http://doi.org/10.1163/156853985x00028

Newberry, R. C., \& Wood-Gush, D. G. M. (1986). Social relationships of piglets in a semi-natural environment. Animal Behaviour, 34(5), 1311-1318. https://doi.org/10.1016/S0003-3472(86)80202-0

Newberry, R. C., Wood-Gush, D. G. M., \& Hall, J. W. (1988). Playful behaviour of piglets. Behavioural Processes, 17(3), 205-216. https://doi.org/10.1016/03766357(88)90004-6

Parker, G. A. (1974). Assessment strategy and the evolution of fighting behaviour. Journal of theoretical Biology, 47(1), 223-243. https://doi.org/10.1016/00225193(74)90111-8

Parker, G. A., \& Rubenstein, D. I. (1981). Role assessment, reserve strategy, and acquisition of information in asymmetric animal conflicts. Animal Behaviour, 29(1), 221240. https://doi.org/10.1016/S0003-3472(81)80170-4 
Parker, G. A., \& Stuart, R. A. (1976). Animal behavior as a strategy optimizer: evolution of resource assessment strategies and optimal emigration thresholds. The American Naturalist, 110(976), 1055-1076. https://doi.org/10.1086/283126 Parratt, C. A., Chapman, K. J., Turner, C., Jones, P. H., Mendl, M. T., \& Miller, B. G.

(2006). The fighting behaviour of piglets mixed before and after weaning in the presence or absence of a sow. Applied Animal Behaviour Science, 101(1-2), 54-67. https://doi.org/10.1016/j.applanim.2006.01.009

Payne, R. J. (1998). Gradually escalating fights and displays: the cumulative assessment model. Animal Behaviour, 56(3), 651-662. https://doi.org/10.1006/anbe.1998.0835

Payne, R. J., \& Pagel, M. (1996). Escalation and time costs in displays of endurance. Journal of Theoretical Biology, 183(2), 185-193. https://doi.org/10.1006/jtbi.1996.0212 Payne, R. J., \& Pagel, M. (1997). Why do animals repeat displays? Animal Behaviour, 54(1), 109-119. https://doi.org/10.1006/anbe.1996.0391

Peden, R. S., Turner, S. P., Boyle, L. A., \& Camerlink, I. (2018). The translation of animal welfare research into practice: the case of mixing aggression between pigs. Applied Animal Behaviour Science, 204, 1-9. https://doi.org/10.1016/j.applanim.2018.03.003

Pellis, S. M. (1981). A description of social play by the Australian magpie Gymnorhina tibicen based on Eshkol-Wachman notation. Bird Behavior, 3(3), 61-79. https://doi.org/10.3727/015613881791560685

Pellis, S. M., Field, E. F., Smith, L. K., \& Pellis, V. C. (1997). Multiple differences in the play fighting of male and female rats. Implications for the causes and functions of play. 
Neuroscience \& Biobehavioral Reviews, 21(1), 105-120. https://doi.org/10.1016/01497634(95)00060-7

Pellis, S. M., Pellis, V. C., \& Bell, H. C. (2010). The function of play in the development of the social brain. American Journal of Play, 2(3), 278-296.

https://eric.ed.gov/?id=EJ1069225

Petersen, H. V., Vestergaard, K., \& Jensen, P. (1989). Integration of piglets into social groups of free-ranging domestic pigs. Applied Animal Behaviour Science, 23(3), 223-236. https://doi.org/10.1016/0168-1591(89)90113-5

Petit, O., Bertrand, F., \& Thierry, B. (2008). Social play in crested and Japanese macaques: Testing the covariation hypothesis. Developmental Psychobiology: The Journal of the International Society for Developmental Psychobiology, 50(4), 399-407. https://doi.org/10.1002/dev.20305

Poirier, F. E., \& Smith, E. O. (1974). Socializing functions of primate play. American Zoologist, 14(1), 275-287. https://doi.org/10.1093/icb/14.1.275

Prenter, J., Elwood, R. W., \& Taylor, P. W. (2006). Self-assessment by males during energetically costly contests over precopula females in amphipods. Animal Behaviour, 72(4), 861-868. https://doi.org/10.1016/j.anbehav.2006.01.023

Rothstein, A., \& Griswold, J. G. (1991). Age and sex preferences for social partners by juvenile bison bulls, Bison bison. Animal Behaviour, 41(2), 227-237. https://doi.org/10.1016/S0003-3472(05)80474-9

Schenkel, R. (1966). Play, exploration and territoriality in the wild lion. Symposia of the Zoological Society of London, 18, 11-22. 
Sharpe, L. L. (2005). Play fighting does not affect subsequent fighting success in wild meerkats. Animal Behaviour, 69(5), 1023-1029.

https://doi.org/10.1016/j.anbehav.2004.07.013

Signoret, J.P., Baldwin, B.A., Fraser, D. and Hafez, E.S.E. (1975). The behaviour of swine in E.S.E. Hafez (ed.), Behaviour of Domestic Animals (pp. 295-329). London, U.K.: Baillière Tindall.

Smith, P. K. (1982). Does play matter? Functional and evolutionary aspects of animal and human play. Behavioral and brain sciences, 5(1), 139-155.

https://doi.org/10.1017/S0140525X0001092X

Špinka, M., Newberry, R. C., \& Bekoff, M. (2001). Mammalian play: training for the unexpected. The Quarterly Review of Biology, 76(2), 141-168.

https://doi.org/10.1086/393866

Stamps, J. A., \& Krishnan, V. V. (1994). Territory acquisition in lizards: I. First encounters. Animal Behaviour, 47(6), 1375-1385.

https://doi.org/10.1006/anbe.1994.1185.

Stolba, A., \& Wood-Gush, D. G. M. (1989). The behaviour of pigs in a semi-natural environment. Animal Science, 48(2), 419-425.

https://doi.org/10.1017/S0003356100040411

Stuart-Fox, D. M., \& Johnston, G. R. (2005). Experience overrides colour in lizard contests. Behaviour, 142(3), 329-350.

https://www.researchgate.net/profile/Gregory_Johnston/publication/46026384_Experienc e_overrides_colour_in_lizard_contests/links/5ae1d2b1aca272fdaf8e7029/Experienceoverrides-colour-in-lizard-contests.pdf 
Stutt, A.D. \& Wilmer, P (1998). Territorial defence in speckled wood butterflies: do the hottest males always win? Animal Behaviour, 55(5), 1341-1347.

806 https://doi.org/10.1006/anbe.1998.0728

807

Taylor, P. W., \& Elwood, R. W. (2003). The mismeasure of animal contests. Animal Behaviour, 65(6), 1195-1202. https://doi.org/10.1006/anbe.2003.2169

Thompson, K. V. (1998). Self assessment in juvenile play in M. Bekoff \& J.A. Byers (eds.), Animal Play: Evolutionary, Comparative, and Ecological Perspectives (pp. 183204). Cambridge, U.K.: Cambridge University Press.

Tisdell, C.A. (1982). Wild pigs: environmental pest or economic resource? Sydney, Australia: Pergamon Press.

Trezza, V., Baarendse, P. J., \& Vanderschuren, L. J. (2010). The pleasures of play: pharmacological insights into social reward mechanisms. Trends in pharmacological sciences, 31(10), 463-469. https://doi.org/10.1016/j.tips.2010.06.008

Verdon, M., Morrison, R. S., \& Hemsworth, P. H. (2016). Rearing piglets in multi-litter group lactation systems: effects on piglet aggression and injuries post-weaning. Applied Animal Behaviour Science, 183, 35-41. https://doi.org/10.1016/j.applanim.2016.05.008 Wattanakul, W., Stewart, A. H., Edwards, S. A., \& English, P. R. (1997). Effects of grouping piglets and changing sow location on suckling behaviour and performance. Applied Animal Behaviour Science, 55(1-2), 21-35. https://doi.org/10.1016/S01681591(97)00020-8

Watson, D. M., \& Croft, D. B. (1993). Playfighting in captive red-necked wallabies, Macropus rufogriseus banksianus. Behaviour, 219-245.

https://doi.org/10.1163/156853993x00128 

and its effect on play behaviour and aggression in the domestic pig (Sus scrofa). Scientific reports, 9(1), 4180. https://doi.org/10.1038/s41598-019-40980-1

Wilson, J. D. (1992). Correlates of agonistic display by great tits Parus major. Behaviour, 168-214. https://doi.org/10.1163/156853992x00363

832

833

Zamudio, K. R., Huey, R. B., \& Crill, W. D. (1995). Bigger isn't always better: body size, developmental and parental temperature and male territorial success in Drosophila melanogaster. Animal Behaviour, 49(3), 671-677. https://doi.org/10.1016/00033472(95)80200-2

Zucker, N., \& Murray, L. (1996). Determinants of dominance in the tree lizard Urosaurus ornatus: the relative importance of mass, previous experience and coloration. Ethology, 102(6), 812-825. https://doi.org/10.1111/j.1439-0310.1996.tb01203.x

9

(1)

(1)

\section{3}

.

46 7

\section{.}

so 51 32 s3 
Table 1 A comparison of winner, loser and combined play-fighting experience of dyads that performed each level of contest escalation

857 compared to those that did not

\begin{tabular}{|lcccccc|}
\hline & \multicolumn{2}{c}{ Winner } & \multicolumn{2}{c}{ Loser } & \multicolumn{2}{c|}{ Combined } \\
& $F_{1,58}$ & $P$ & $F_{1,58}$ & $P$ & $F_{1,58}$ & $P$ \\
\hline Display & 0.501 & 0.482 & 0.146 & 0.704 & 0.033 & 0.85860 \\
Nondamaging & 0.938 & 0.337 & 6.560 & $0.013^{*}$ & 4.855 & $0.031^{*}$ \\
aggression & & & & & & 861 \\
Mutual fighting & 0.968 & 0.329 & 3.744 & 0.058 & 3.298 & 0.0752 \\
\hline
\end{tabular}

863

$\underline{\text { Asterisks indicate significant } P \text { values. }}$ 
Table 2 A comparison of the preweaning play-fighting experience of the initiating individual of each stage of contest behaviour and the recipient 868

\begin{tabular}{|lccccccc|}
\hline & \multicolumn{2}{c}{ Initiator } & \multicolumn{2}{c}{ Recipient } & & & \\
& Mean & SE & Mean & SE & $t$ & $d f$ & $P$ \\
\hline Display & 27.800 & 2.464 & 25.545 & 1.999 & 0.922 & 54 & 0.361 \\
Nondamaging & 30.600 & 3.306 & 27.325 & 2.616 & 0.704 & 39 & 0.485 \\
aggression & & & & & & & \\
Biting & 28.172 & 2.344 & 25.953 & 1.991 & 0.744 & 63 & 0.460 \\
Mutual fighting & 27.741 & 2.364 & 28.574 & 2.563 & -0.293 & 53 & 0.770 \\
\hline
\end{tabular}

870 Play-fighting experience is the number of all successful play-fighting invites made plus the 871 number of accepted play-fighting invites received. 
Table $3 \beta$ values depicting the effect strength of winner and loser play-

875 fighting experience on eight measures of contest costs provided for

\begin{tabular}{|lcccccc|}
\hline & \multicolumn{2}{c}{ Socialized dyads } & \multicolumn{2}{c|}{ Control dyads } & \multicolumn{2}{c|}{ All dyads } \\
& $\begin{array}{c}\text { Winner } \\
\text { play }\end{array}$ & $\begin{array}{c}\text { Loser } \\
\text { play }\end{array}$ & $\begin{array}{c}\text { Winner } \\
\text { play }\end{array}$ & $\begin{array}{c}\text { Loser } \\
\text { play }\end{array}$ & $\begin{array}{c}\text { Winner } \\
\text { play }\end{array}$ & $\begin{array}{c}\text { Loser } \\
\text { play }\end{array}$ \\
\hline Contest duration $^{\mathrm{a}}$ & 0.01 & $<0.01$ & -0.02 & 0.01 & $-0.2^{-6}$ & $<0.001$ \\
Duration of mutual fighting a & 0.04 & 0.03 & -0.01 & 0.01 & 0.01 & $<0.01$ \\
Winner skin lesions $^{\mathrm{b}}$ & 0.02 & 0.01 & -0.05 & 0.01 & 0.02 & 0.01 \\
Loser skin lesions $^{\mathrm{b}}$ & 0.03 & -0.02 & -0.04 & -0.02 & 0.01 & -0.20 \\
PI winner blood glucose $^{\mathrm{a}}$ & $<0.01$ & $-0.1^{-2}$ & $<0.01$ & $<0.01$ & $<0.01$ & $<0.01$ \\
PI loser blood glucose $^{\mathrm{a}}$ & $<0.01$ & $<0.01$ & $<0.01$ & $<0.01$ & $<0.01$ & $<0.01$ \\
PI winner blood lactate $^{\mathrm{a}}$ & 0.01 & $<0.01$ & 0.01 & 0.01 & 0.01 & 0.01 \\
PI loser blood lactate $^{\mathrm{a}}$ & 0.01 & 0.01 & $<0.01$ & 0.01 & 0.01 & 0.01 \\
\hline
\end{tabular}

PI: proportional increase.

aThe dependent variable was log transformed. 
Table A1 Ethogram for identifying play fighting during video playback

\begin{tabular}{|ll|}
\hline Behaviour & Description \\
\hline Play-fighting invite & $\begin{array}{l}\text { Initiator piglet performs rapid face-to-face pushing actions directed at a target } \\
\text { piglet. Pushing is often repetitive and performed in an energetic manner. Does not } \\
\text { include deliberate/accidental shoving when the target pig is inhibiting initiator } \\
\text { locomotion. All pushing and shoving under the udder is ignored during suckling } \\
\text { bouts } \\
\text { Target piglet responds to the initiator piglets 'invite' by pushing back and } \\
\text { engaging in a play response. Play occurs as both individuals push towards each } \\
\text { other, with occasional head knocking and biting attempts. (See Accept play } \\
\text { fighting) }\end{array}$ \\
Failure & $\begin{array}{l}\text { Initiator is unsuccessful at eliciting a play response from the target individual. } \\
\text { Target piglet either turns its head/body away from the initiator piglet, moves } \\
\text { away without further reaction, or does not give any noticeable response to the } \\
\text { initiator piglet's attempts to play. (See Reject play fighting) } \\
\text { Target piglet responds to initiator piglet's invite by pushing back against the head } \\
\text { of the initiator. This results in both individuals pushing towards each other, with } \\
\text { occasional head knocking and biting attempts. (See Success) } \\
\text { Target piglet does not response to initiator piglet. Target piglet either turns its } \\
\text { head/body away from the initiator piglet, moves away without further reaction, or } \\
\text { does not give any noticeable response to the initiator piglet's attempts to play. } \\
\text { (See Failure) } \\
\text { A third piglet attempts to join a play fight by either pushing one or both of the } \\
\text { participating piglets. This interaction either results in the play behaviour finishing, } \\
\text { one piglet being displaced from the play fight, or the continuation of the fight } \\
\text { with a third member }\end{array}$ \\
\hline Third-party interaction
\end{tabular}

Ethogram adapted from Weller et al., 2019. 
Table A2 - Ethogram for dyadic contests, identifying four stages of escalation and the individual behaviours comprising them

\begin{tabular}{|c|c|}
\hline Behaviour & Description \\
\hline \multicolumn{2}{|l|}{ Start/contact } \\
\hline Naso-body contact & $\begin{array}{l}\text { Pig's nose approaches within } 5 \mathrm{~cm} \text { of the body of the opponent excluding the } \\
\text { snout area (i.e. facial area below the eyes) }\end{array}$ \\
\hline Naso-naso contact & $\begin{array}{l}\text { Pig's nose approaches within } 5 \mathrm{~cm} \text { of the snout area (i.e. facial area below the } \\
\text { eyes) }\end{array}$ \\
\hline \multicolumn{2}{|l|}{ Display behaviour } \\
\hline Investigation & $\begin{array}{l}\text { Light touch to the body of the opponent (including sniffing), especially directed } \\
\text { towards ears, eyes, face and rear end. Does not include any forceful contact or } \\
\text { biting while in any orientation }\end{array}$ \\
\hline Heads up & $\begin{array}{l}\text { Both pigs have their nose/head lifted high up in the air in either parallel or } \\
\text { frontal orientation while still }\end{array}$ \\
\hline Parallel walking & $\begin{array}{l}\text { Both pigs walk forward simultaneously and deliberately with their shoulders } \\
\text { and heads level. May also have noses/heads up }\end{array}$ \\
\hline Shoulder-to-shoulder & $\begin{array}{l}\text { Both pigs are standing shoulder against shoulder, either facing the same } \\
\text { orientation or adopting a tail-to-nose orientation, without applying pressure to } \\
\text { the shoulder (i.e. not pushing) }\end{array}$ \\
\hline \multicolumn{2}{|l|}{ Nondamaging behaviour } \\
\hline Pushing & $\begin{array}{l}\text { Either pig uses its head or shoulder to move its opponent while putting pressure } \\
\text { on the opponent's shoulder. Can be performed by one or both pigs } \\
\text { simultaneously. }\end{array}$ \\
\hline Nose wrestling & $\begin{array}{l}\text { Both pigs firmly press the side of their nose against the side of the opponent's } \\
\text { nose }\end{array}$ \\
\hline Head knock & $\begin{array}{l}\text { Either pig rapidly swings its head to deliver a blow to the opponent. It may or } \\
\text { may not involve a small bite (also recorded accordingly, see Biting). }\end{array}$ \\
\hline Shove & $\begin{array}{l}\text { Either pig uses its snout or head to apply continued pressure to its opponent, } \\
\text { resulting in the opponent being moved along or lifted off the floor }\end{array}$ \\
\hline Flick or nip & $\begin{array}{l}\text { Either pig performs a small side-nipping action of the teeth or a small rapid } \\
\text { forceful movement with the head/snout. Either behaviour does not result in a } \\
\text { full bite }\end{array}$ \\
\hline Biting & Pig opens its mouth and delivers a bite which contacts and injures the opponent \\
\hline Mutual fighting & $\begin{array}{l}\text { Either pig is aggressive towards its opponent, which in turn retaliates } \\
\text { aggressively within } 5 \mathrm{~s} \text {. This behaviour then continues until either pig retreats } \\
\text { (See Other behaviours) or any of the above behaviours is performed/resumed. } \\
\text { Pigs may return to mutual fighting several times. Any single component of } \\
\text { behaviour performed during mutual fighting (i.e. biting or pushing) is not } \\
\text { counted as a separate behaviour outside of mutual fighting. }\end{array}$ \\
\hline \multicolumn{2}{|l|}{ Additional behaviours } \\
\hline Head tilt with retreat & $\begin{array}{l}\text { Losing individual turns its head away from the opponent and retreats from } \\
\text { further attacks. Considered successful if retreating individual does not retaliate } \\
\text { within } 1 \text { min of retreating }\end{array}$ \\
\hline
\end{tabular}


Mounting

Bullying
One pig lifts both front legs from the ground and over the back, rear, side or head of the opponent

One pig continues to pursue the other, chasing and biting/attempting to bite as the other withdraws and attempts to escape from, body block, or avoid contact with the pursuing pig

Ethogram adapted from Camerlink et al., 2016. 
889

890

891

892

893

894

895

896

897

898

899

900

901

902

903

904

905

906

907

908

Figure 1 - Logistic regression demonstrating how the weight difference of competitors affected contest outcome. Circles on the probability value 0 represent contests that the focal individual lost while circles on the probability value 1 represent contests that the focal individual won.

Figure 2 - The preweaning play-fighting experience of winners and losers compared for males and females. Play-fighting experience is the number of all successful playfighting invites made plus the number of accepted play-fighting invites received. Error bars represent the SEM.

Figure 3 - A comparison of the winner, loser and combined play-fighting experience of dyads that performed a stage of nondamaging (ND) aggression and those that did not. Play-fighting experience is the number of all successful play-fighting invites made plus the number of accepted play-fighting invites received. Error bars represent the SEM.

Figure 4 - The effect of winner and loser play-fighting experience on the number of skin lesions losing individuals received over the course of the contest in (a) socialized dyads and (b) control dyads. Play-fighting experience is the number of all successful play-fighting invites made plus the number of accepted play-fighting invites received. Trend lines indicate lines of best fit. 